\title{
Differential Relaxing Response of Various Arterial Smooth Muscles of Dogs to Nifedipine
}

\author{
Nobuharu Akatsuka, M.D.
}

\section{SUMMARY}

Differences in the relaxing effects of nifedipine, a so-called calcium antagonist, were studied in smooth muscle from different arteries of dogs. The common carotid artery (Car A), celiac artery (Cel A), superior mesenteric artery (SMA), renal artery (RA), femoral artery (FA), and coronary artery (Cor A) were helically cut, and their developed isometric tensions were recorded. High potassium contraction was induced in these strips, and, at the peak of developed tension, nifedipine $\left(10^{-6} \mathrm{M}\right)$ was added. Relaxation curves induced by nifedipine were analyzed by a curve fitting method into two to three exponentials.

The general form of the equation is $A_{t}=\sum_{i=1}^{2 \text { or } 3} A_{0} e^{-k i t}$. The $k$ value shows the rate of relaxation; i.e., the larger the value the faster the relaxation. The relaxation was faster in the order of $\mathrm{RA}$, SMA, Cor A, Cel A, Car A, and FA. The value of $\left(A_{0 i} / \sum_{i=1}^{2 \text { or } 3} A_{0 i}\right) \times$ 100 shows the fraction of tension in each component of the relaxation curve $\mathrm{A}_{0 \mathrm{i}} \mathrm{e}^{-\mathrm{kit}}$. The fraction of tension distributed to the faster relaxation exponentials $\left[\mathrm{A}_{02} \mathrm{e}^{-\mathrm{k} 2 \mathrm{t}}\left(+\mathrm{A}_{03} \mathrm{e}^{-\mathrm{k} 3 \mathrm{t}}\right)\right]$ in each smooth muscle was larger in the order of RA, SMA, Cor A, Car A, FA, and Cel A.

\section{Additional Indexing Words:}

High potassium contraction Curve fitting method Exponentials

$7 \mathrm{HE}$ use of calcium antagonists, such as verapamil, ${ }^{1,2)}$ nifedipine $^{31,4)}$ or diltiazem ${ }^{5)}$ has been considered in clinical practice to control the afterload in advanced hypertension. In this clinical condition, the possible redistribution of blood flow caused by the administration of a calcium an-

From the First Department of Internal Medicine, Faculty of Medicine, University of Tokyo, Tokyo.

Address for reprint: Nobuharu Akatsuka, M.D., First Department of Internal Medicine, Faculty of Medicine, University of Tokyo, Hongo 7-3-1, Bunkyo-ku, Tokyo 113, Japan.

Received for publication June 22, 1982.

Manuscript revised September 16, 1982. 
tagonist may have a substantial influence on the efficacy and the limitations of the therapy. Although contractile heterogeneity among smooth muscles from different anatomical locations is well recognized, the effects of these drugs on individual vascular beds have not been studied. The purpose of this study was to examine the differences in sensitivity of smooth muscles of main arterial branches (i.e., conductance vessels to various organs) to nifedipine.

\section{METHODS}

Mongrel dogs $(n=15)$ of either sex were killed by exsanguination under anesthesia (pentobarbital sodium $30 \mathrm{mg} / \mathrm{Kg}$, i.v.). Their common carotid arteries, celiac arteries, superior mesenteric arteries, renal arteries, femoral arteries, and anterior descending branches of the left coronary artery were immediately removed and placed in an ice-cold physiological salt solution (PSS). Two to three kinds of vessels were obtained from each dog in a random combination. The vessels were cleaned of blood and surrounding loose connective tissue. Helical strips (about $1 \times 15 \mathrm{~mm}$ for coronary arteries and about $1.5 \times 20 \mathrm{~cm}$ for other vessels; $\mathrm{n}=5$ for each vessel) were cut according to the method of Furchgott and Bhadrakom, ${ }^{6)}$ and were attached by one end to a stationary acrylic rod inside a 10-ml acrylic muscle bath. The other end was attached to a force displacement transducer (FD Pickup SB1T, Nihon Kohden Co, Tokyo, Japan) connected to a Recticorder (Nihon Kohden Co), which gave a continuous recording of isometric tension. The bath contained PSS of the following millimolar composition: $\mathrm{NaCl} 114$, $\mathrm{MgSO}_{4} 1.2, \mathrm{CaCl}_{2} 1.9, \mathrm{KCl} 5, \mathrm{NaHCO}_{3} 25, \mathrm{KH}_{2} \mathrm{PO}_{4} 1.2$, and dextrose 5.5. The PSS was bubbled with $95 \% \mathrm{O}_{2}$ and $5 \% \mathrm{CO}_{2}$ and was maintained at $37^{\circ} \mathrm{C}$ and $\mathrm{pH}$ 7.4. The strips were allowed to equilibrate for at least 2 hours. The load was adjusted to $1 \mathrm{Gm}$ for all arteries except for coronary arteries, and a cumulative dose-response curve for norepinephrine $\left(10^{-9}\right.$ through $10^{-5} \mathrm{M}$ ) was measured to examine the contractility of a strip. For the coronary artery, load was adjusted to $0.4 \mathrm{Gm}$ and high potassium contraction was induced to examine the contractility of a strip.

After the test of the contractility of each strip by a cumulative norepinephrine-induced contraction, a high potassium contraction was induced in all strips to obtain a control curve. The high potassium solution was of the following millimolar composition: $\mathrm{NaCl} 39, \mathrm{MgSO}_{4} 1.2, \mathrm{CaCl}_{2} 1.9, \mathrm{KCl}$ 80, $\mathrm{NaHCO}_{3} 25, \mathrm{KH}_{2} \mathrm{PO}_{4} 1.2$, and dextrose 5.5. At the peak of the second high potassium contraction, a nifedipine solution of $10^{-6} \mathrm{M}$ (final concentration) in the bath was applied to each tissue (ethanol $0.01 \%$ in the bath). 
The relaxation curves induced by the addition of nifedipine were recorded for at least $45 \mathrm{~min}$ and the developed tension was measured every minute and calculated as the percent of the peak developed tension. The relaxation curves were then plotted on semilogarythmic paper and were analyzed using the least square curve fitting method. Two to three exponentials were calculated for each relaxation curve. The general form of the equation describing such a series of two to three exponential curves is:

$$
\mathrm{At}=\sum_{i=1}^{\mathrm{n}} \mathrm{A}_{0 \mathrm{i}} \mathrm{e}^{-\mathrm{kit}}(\mathrm{n}=2 \text { or } 3)
$$

where $A_{t}$ : precent of the initial tension at $t$ minutes after the onset of the application of nifedipine to an arterial strip; $\mathrm{A}_{0 \mathrm{i}}$ : developed initial percentile tension attributed to the component $i$ exponential, as determined by the intercept of each curve with the ordinate; $\mathrm{k}_{\mathrm{i}}$ : the slope of the curve of component i. A value of $\left(\mathrm{A}_{0 \mathrm{i}} / \sum_{\mathrm{i}=1}^{2 \text { or } 3} \mathrm{~A}_{0 \mathrm{i}}\right) \times 100$ was also calculated. This number shows the percent of the initial tension attributable to each component of the $\mathrm{A}_{0 \mathrm{i}} \mathrm{e}^{-\mathrm{kit}}$ curve. Results are expressed as means $\pm \mathrm{SEM}$, and the statistical significance was determined by the use of a paired or unpaired Student's $t$ test.

\section{REsults}

The calculations of nifedipine-induced relaxation curves yielded three exponentials for the renal and the superior mesenteric arteries, and two exponentials for the celiac, the common carotid, the femoral and the coronary arteries. The $\mathrm{k}$ values of all arteries are shown in the Table $\mathrm{I}$. The statistical analyses of $k_{1}$ values showed significant differences between the renal and the celiac arteries $(\mathrm{p}<0.05)$, the coronary and the superior mesenteric

Table I.

\begin{tabular}{c|l|c|c|c|c|c|c}
\hline \multicolumn{2}{c|}{} & RA & SMA & Cor A & Cel A & Car A & FA \\
\hline \multirow{2}{*}{$k_{1}$} & Mean & 0.004 & 0.017 & 0 & 0.019 & 0.007 & 0.006 \\
& S.E. & 0.005 & 0.005 & 0 & 0.005 & 0.005 & 0.005 \\
\hline \multirow{2}{*}{$k_{2}$} & Mean & 0.206 & 0.264 & 0.520 & 0.364 & 0.193 & 0.153 \\
& S.E. & 0.033 & 0.033 & 0.029 & 0.042 & 0.028 & 0.014 \\
\hline \multirow{2}{*}{$k_{3}$} & Mean & 0.837 & 0.657 & & & & \\
& S.E. & 0.219 & 0.099 & & & &
\end{tabular}

The mean $k_{1}, k_{2}$, and $k_{3}$ values of exponentials calculated from nifedipine-induced relaxation curves of vascular smooth muscle strips ( $n=5$ in each), which were contracted beforehand by a high potassium solution. $P$ values see text. 
Table II.

\begin{tabular}{c|l|r|r|r|r|r|r}
\hline \multicolumn{2}{l|}{} & \multicolumn{1}{c|}{ RA } & SMA & Cor A & Gel A & Car A & FA \\
\hline \multirow{2}{*}{$\mathrm{A}_{01}$ fraction } & Mean & 4.62 & 11.10 & 22.34 & 33.56 & 29.52 & 30.56 \\
& S.E. & 0.95 & 1.38 & 5.18 & 9.10 & 2.48 & 5.28 \\
\hline \multirow{2}{*}{$\mathrm{A}_{02}\left(+\mathrm{A}_{03}\right)$} & Mean & 95.38 & 88.90 & 77.66 & 66.44 & 70.48 & 69.44 \\
fraction & S.E. & 0.95 & 1.38 & 5.18 & 9.10 & 2.48 & 5.28
\end{tabular}

The mean $A_{01}$ fraction and $A_{02}\left(+A_{03}\right.$ ) fraction values of exponentials calculated from nifedipine* induced relaxation curves of vascular smooth muscle strips $(n=5$ in each) which were contracted beforehand by a high potassium solution. $P$ values in $A_{01}$ fractions and in $A_{02}\left(+A_{03}\right)$ fractions: RA vs: $S M A<0.005$, Cor $A<0.01$, Cel $A<0.01$, Car $A<0.001$, FA<0.001; SMA vs : Cor $A<0.05$, Cel $A<0.05$, Car $A<0.001, F A<0.005$. Others: nonsignificant. $A_{01}$ fraction and $A_{02}\left(+A_{03}\right)$ fraction see text.

arteries $(\mathrm{p}<0.005)$ and the coronary and the celiac arteries $(\mathrm{p}<0.005)$. There were also significant differences in $k_{2}$ values between the renal and the celiac arteries $(p<0.025)$. The $k_{2}$ value for the coronary artery was larger than the remaining arterial $k_{2}$ values $\left(p<0.001\right.$ each). The $k_{2}$ of the celiac artery was larger than that of the common carotid $(p<0.005)$ and the femoral arteries $(p<0.001)$. The $k_{3}$ values of the renal and the superior mesenteric arteries showed no significant difference. The renal artery showed the smallest $\left(A_{01} / \sum_{i=1}^{2 \text { or } 3} A_{0 i}\right) \times 100$ value $\left(A_{01}\right.$ fraction) (Table $\left.I I\right)$. There was no significant difference in this fraction among the celiac, common carotid, femoral and the coronary arteries. The $\left[A_{02}\left(+A_{03}\right) / \sum_{i=1}^{2 \text { or } 3} A_{0 i}\right] \times 100$ value $\left[\left(A_{02}\left(+A_{03}\right)\right.\right.$ fraction)] for the renal artery was the largest and values for the celiac, common carotid, femoral and coronary arteries were not significantly different.

Thcse results show that nifedipine induces a rapid, nearly complete relaxation of the renal and the superior mesenteric arteries, and that it induces a rapid but limited relaxation of the coronary artery. In the other arteries examined in this study, nifedipine induces a relatively slow and limited relaxation.

\section{Discussion}

Grün and Fleckenstein ${ }^{7 /}$ reported that nifedipine abolished the autoregulation of an isolated rabbit ear artery. It has been suggested that the calcium source utilized in the autoregulatory vascular control is of an extracellular origin. ${ }^{8)}$ Thus, the influx of extracellular calcium ions plays an important role in the regulation of vascular smooth muscle tone. Nifedipine has been suggested to selectively inhibit the influx of extracellular calcium ions through the cell membrane. ${ }^{91}$ 


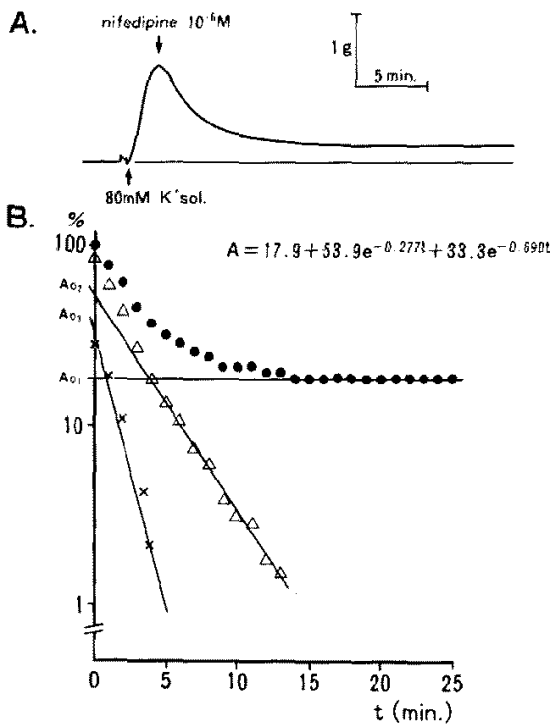

Fig. 1. Nifedipine-induced relaxation curve of a renal arterial strip contracted in the presence of a high-potassium solution (A), and the analysis with a curve-fitting method (B).

A high potassium concentration in an incubation medium causes depolarization of the membrane of vascular smooth muscle, inducing a contraction. The plateau phase of the high potassium contraction may be considered as a state of equilibrium for calcium binding and removal of calcium from the contractile elements. When we completely interrupt the influx of calcium ions at the peak of a high potassium contraction, the relaxation curve may be considered to show the removal rate of calcium ions from the contractile mechanism. Thus, a difference in the rate of relaxation may reflect a difference in the rate of removal of calcium ions from the contractile mechanism of each vascular smooth muscle tissue. However, it is also conceivable that differential nifedipine sensitivity of smooth muscle from different arteries could produce different relaxation curves for each tissue, (with changes in $A_{01}$ values), without underlying differences in the removal rate of calcium ions. Hashimoto et $\mathrm{al}^{\mathbf{1 0}}$ ) reported that the affinity to nifedipine differed considerably in each vascular tissue. Thus, $\mathrm{A}_{0 \mathrm{i}}$ values are affected by the amount of nifedipine-sensitive calcium ions and the nifedipine affinity of each tissue. Therefore, specific conclusions about the amount of nifedipinesensitive calcium ions in the various tissues cannot be made in the present study.

Analyses of the relaxation curves of smooth muscle strips yielded two to three components. Relaxation curves of smooth muscle strips which showed 


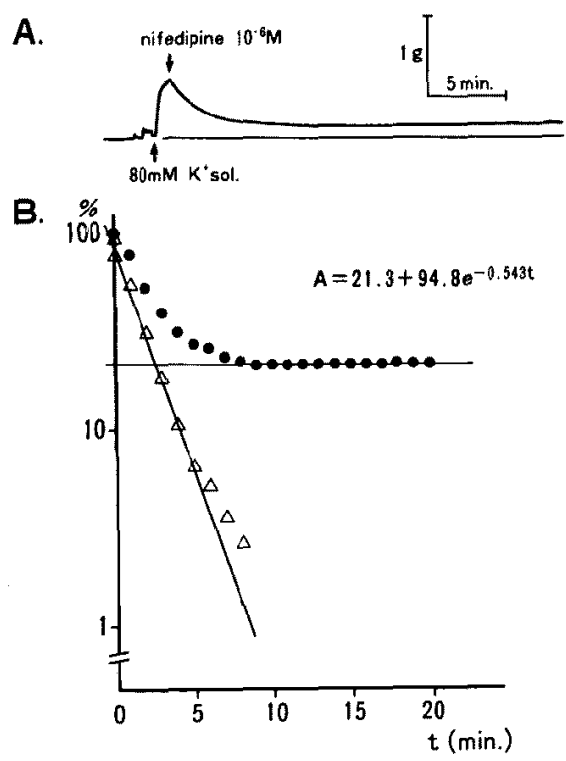

Fig. 2. Nifedipine-induced relaxation curve of a coronary arterial strip contracted in the presence of a high-potassium solution (A), and its analysis with a curve-fitting method (B).

rapid relaxation (renal and superior mesenteric arteries, Fig. 1) were generally composed of three components. Although the $\mathrm{k}_{2}$ value was largest for the coronary artery, the relaxation curve was composed of only two components (Fig. 2). Since the coronary artery had the thinnest vascular wall, the availability of the third component is not dependent upon the thickness of the arterial wall. The $k_{2}$ value for the coronary artery may actually include both the $k_{2}$ and $k_{3}$ values, since the $A_{03}$ is so small that a third component could not be differentiated.

The $k_{1}$ values showed statistically significant differences between the celiac artery and the renal artery, and between the coronary artery and the superior mesenteric and celiac arteries. The $\left(A_{01} / \sum_{i=1}^{2 \text { or } 3} A_{0 i}\right) \times 100$ value $\left(A_{01}\right.$ fraction) of the renal artery was the smallest $(4,6)$, showing that the relaxation of the vessel was almost complete during the rapid relaxation phase. On the other hand, the $k_{1}$ of the coronary artery was 0 , and the $A_{01}$ fraction was 22.3 , suggesting that the coronary artery relaxed only to a limited degree with $10^{-6} \mathrm{M}$ of nifedipine. The initial nifedipine-induced rapid relaxation was prominent in the renal, superior mesenteric, celiac, and coronary arteries, as evidenced by the $k_{2}$ and $k_{3}$ values of these vessels.

From these results, it is suggested that the nifedipine-induced relaxation of the renal artery is the most rapid and complete, followed by the superior mesenteric artery. The relaxation of the coronary and celiac arteries is 
also rapid but of a limited degree. The common carotid and femoral arteries showed a slow, limited relaxation. Ekelund ${ }^{11}$ reported that nifedipine increased the renal blood flow (Klütsch et al12) and the hepatic blood flow (Mostbeck et $\mathrm{al}^{13)}$ ) by 6 to $25 \%$. These results may be partly explained by the results obtained in the present study.

Although the mechanisms of smooth muscle contraction induced by norepinephrine and a high potassium solution are not identical, ${ }^{14)}$ nifedipine inhibits contraction in both of these conditions. These data then, suggest that nifedipine causes nonspecific inhibition of the calcium flux of smooth muscle cells. If the dependence of vascular smooth muscle cells on the influx of extracellular calcium during contractions is of the same order as shown in this study, represented by the rapidity and extent of relaxation of each tissue, then the drug should be expected to have beneficial effect in the treatment of congestive heart failure and hypertension with impaired renal and coronary circulation.

\section{References}

I. Brittinger DW, Strauch M, Huber W, Koch WD, Henning GE, Wittenmeier KW, Twittenhoff WD: Iproveratril als Antihypertonikum bei krisenhafter renaler Hypertonie. Dtsch med Wschr 94: 945, 1969

2. Bender von F: Die Behandlung der tachycarden Arrhythmien und der arteriellen Hypertonie mit Verapamil. Arzneim-Forsch (Drug Res) 20: 1310, 1970

3. Murakami M, Murakami E, Takekoshi N, Tsuchiya M, Kin T, Onoe T, Takeuchi N, Funatsu T, Hara S, Ishise S, Mifune J, Maeda M: Antihypertensive effect of 4(-2'-nitrophenyl)2, 6-dimethyl-1, 4-dihydropyridine-3, 5-dicarbonic acid dimethylester (nifedipine, Bay-a 1040). A new coronary dilator. Jpn Heart J 13: 128, 1972

4. Aoki K, Yoshida T, Kato S, Tazumi K, Sato I, Takikawa K, Hotta K: Hypotensive action and increased plasma renin activity by $\mathrm{Ca}$ antagonist (nifedipine) in hypertensive patients. Jpn Heart J 17: 479, 1976

5. Ikeda M: Double-blind studies on diltiazem in essential hypertensive patients receiving thiazide therapy. in New Drug Therapy with a Calcium Antagonist, ed by Bing RJ, Excerpta Medica, Amsterdam-Princeton, p 243-253, 1978

6. Furchgott RF, Bhadrakom S: Reactions of strips of rabbit aorta to epinephrine, isopropylarterenol, sodium nitrite and other drugs. J Pharmacol Exp Therap 108: 129, 1953

7. Grün G, Fleckenstein A: Die clektromechanische Entkoppelung der glatten Gefässmuskulatur als Grundprinzip der Coronardilatation durch 4-(2'-Nitrophenyl)-2, 6-dimethyl-1, 4dihydropyridin-3, 5-dicarbonsäure-dimethylester (BAY a 1040, Nifedipine). I. Die Bedeutung der $\mathrm{Ca}^{++}$-Ionen für die bioelektrische und mechanische Aktivität der glatten Muskulatur. Arzneim-Forsch (Drug Res) 22: 334, 1972

8. Ono $\mathrm{H}$, Kokubun $\mathrm{H}$, Hashimoto $\mathrm{K}$ : Abolition by calcium antagonists of the autoregulation of renal blood flow. Naunyn-Schmiedeberg's Arch Pharmacol 285: 201, 1974

9. Fleckenstein A, Tritthart H, Döring HJ, Byon KY: BAY-a 1040-ein hochaktiver $\mathrm{Ca}^{++}$. antagonistischer Inhibitor der elektro-mechanischen Kopplungsprozesse im WarmblüterMyokard. Arzneim-Forsch (Drug Res) 22: 22, 1972

10. Hashimoto K, Taira N, Chiba S, Hashimoto K Jr, Endoh M, Kokubun M, Kokubun H, Iijima T, Kimura T, Kubota K, Oguro K: Cardiohemodynamic effects of BAY a 1040 in the 
dog. Arzneim-Forsch (Drug Res) 22: 15, 1972

11. Ekelund LG: Ca-blockers and peripheral circulation-physiological viewpoints. Acta Pharmacol Toxicol 43 (Suppl 1): 33, 1978

12. Klütsch K, Schmidt P, Grosswendt J : Der Einfluss von BAY a 1040 auf die Nierenfunktion des Hypertonikers. Arzneim-Forsch (Drug Res) 22: 377, 1972

13. Mostbeck A, Partsch H, Peschl L: Extracardial effects of nifedipine. Measurements of liver blood flow in animals and humans and of peripheral circulation in the lower limbs. 1st International Nifedipine "Adalat" Symposium: New Therapy of Ischemic Heart Disease, ed by Hashimoto K, Kimura E, Kobayashi T, University of Tokyo Press, Tokyo, p 136-143, 1975

14. Hiraoka M, Yamagishi S, Sano T: Role of calcium ions in the contraction of vascular smooth muscle. Am J Physiol 214: 1084, 1968 